\title{
Restoration of the tumor-suppressor function to mutant p53 by Ganoderma lucidum polysaccharides in colorectal cancer cells
}

\author{
DAN JIANG $^{1}$, LINGYAO WANG $^{1}$, TONG ZHAO $^{1}$, ZHAOYU ZHANG $^{1}$, RENXIA ZHANG $^{1}$, \\ JINGJI JIN $^{1-3}$, YONG CAI ${ }^{1-3}$ and FEI WANG ${ }^{1-3}$ \\ ${ }^{1}$ School of Life Sciences, ${ }^{2}$ National Engineering Laboratory for AIDS Vaccine, and \\ ${ }^{3}$ Key Laboratory for Molecular Enzymology and Engineering, The Chinese Ministry of Education, \\ Jilin University, Changchun, Jilin 130012, P.R. China
}

Received May 25, 2016; Accepted July 1, 2016

DOI: $10.3892 / o r .2016 .5246$

\begin{abstract}
Ganoderma lucidum polysaccharides (GLPs), isolated from spores, mycelia and fruiting bodies of Ganoderma lucidum, have been suggested to possess anticancer activities in a large number of basic studies. A recent survey revealed that GLP-induced inhibition of cancer cell growth was dependent on the existence of functional p53. However, the actual role of p53-mediated tumor-suppressing pathways in facilitating the anticancer effect of GLPs is still unclear. In the present study, we investigated the interaction between GLPs and mutant p53 that exists in more than half of the known types of cancers. Our results showed that GLPs reactivated mutant p53 in colorectal cancer HT29 (p53 ${ }^{\mathrm{R} 273 \mathrm{H}}$ ) and SW480 (p53 $\left.{ }^{\mathrm{R} 273 \mathrm{H} \& \mathrm{P} 309 \mathrm{~S}}\right)$ cells while applied alone or together with 5-fluorouracil (5-FU). This reactivation further induced cell growth inhibition and apoptosis. In addition, western blot assay and in vitro cell-free apoptosis assay suggested that the activation of mutant p53 was effective in both a transcriptional-dependent and -independent pathway. Altogether, our data demonstrated for the first time that GLPs show prominent anticancer activities by reactivating several types of mutant p53. Therefore, targeting mutant p53 by GLPs alongside other chemotherapeutics may be considered as a novel treatment strategy for cancer.
\end{abstract}

\section{Introduction}

Ganoderma lucidum, also called 'Ling-Zhi' in China and 'Rei-Shi' in Japan, is a basidiomycete white rot fungus mostly

Correspondence to: Dr Fei Wang, School of Life Sciences, Jilin University, 2699 Qianjin Street, Changchun, Jilin 130012, P.R. China E-mail: fei@jlu.edu.cn

Abbreviations: GLPs, Ganoderma lucidum polysaccharides; 5-FU, 5-fluorouracil; MMP, mitochondrial membrane permeabilization

Key words: Ganoderma lucidum polysaccharides, mutant p53, apoptosis, growth inhibition, human colorectal cancer cells distributed in tropical regions and usually growing on cut or rotten trees (1). Among the many traditional medicines, Ganoderma lucidum has been used for more than 2,000 years for the prevention or treatment of various human diseases (2). Even today, this fungus is still predominantly used by Asian populations to improve well-being and general health (3), as well as to inhibit cancer while used alone or alongside chemotherapy treatment (4-6).

Ganoderma lucidum contains various bioactive molecules, such as triterpenoids, polysaccharides, nucleotides, fatty acids, glycoproteins, sterols, steroids, proteins and peptides $(7,8)$. Among these, Ganoderma lucidum polysaccharides (GLPs), isolated from the spores, mycelia and fruiting bodies of Ganoderma lucidum, have been suggested to possess anticancer effects by a large number of basic studies (9-12). According to the latest laboratory and preclinical studies both in vitro and in vivo, the promising anticancer activity of GLPs can be attributed to a variety of different mechanisms (13). However, clinical studies of GLPs on patients with cancer are limited, and the results are inadequately reported concerning various aspects (14). Therefore, further investigation and evaluation of the mechanism by which GLPs inhibit or kill cancer cells are necessary to potentiate the use of GLPs as a first-line treatment for cancer.

A recent survey of the performance of GLPs on 14 human tumor cells with various p53 status revealed that GLP-induced inhibition of cancer cell growth depends on the existence of functional p53 (15). However, the actual role of p53-mediated tumor-suppressing pathways in facilitating the anticancer effect of GLPs, as well as the interaction between GLPs and mutant p53 that exist in more than half of known cancers remain unclear. In the present study, we chose colorectal cancer cells with different p53 status to analyze the anticancer effect of GLPs administrated alone or together with chemotherapy treatment, as well as the involvement of p53-mediated cell cycle arrest and apoptosis.

\section{Materials and methods}

Antibodies. Anti-p53 (sc-126), anti-Bax (sc-493), anti-p21 (sc-397), anti-SDHB (sc-25851) and anti-cytochrome $c$ (sc-13156) antibodies were purchased from Santa Cruz 
Biotechnology, Inc. (Santa Cruz, CA, USA). Anti-GAPDH and anti-H2B rabbit polyclonal antibodies were raised against bacterially expressed proteins (Jilin University).

Preparation of GLPs. GLPs were isolated and purified from the fruiting body of Ganoderma lucidum (Beijing Tong Ren Tang Group Co., Ltd.) using a procedure as previously described (16). Crude polysaccharide powder was obtained through derosination, hot water extraction, deproteinization, alcohol precipitation and lyophilization. Crude GLP solution $(10 \mathrm{mg} / \mathrm{ml}$ in water) was ultra-filtered through $10-\mathrm{kDa}$ molecular weight cut-off (MWCO) membranes (Millipore, Billerica, MA, USA). The filtrate (molecular weight of polysaccharides $>10 \mathrm{kDa}$ ) was freeze-dried and stored at $-30^{\circ} \mathrm{C}$ for subsequent analysis.

Cell culture and transient transfection. Human colon cancer cell lines HCT-116 $\left(\mathrm{P}^{+/ /+}\right.$and $\left.\mathrm{P} 53^{-/}\right)$were provided by Professor Yinghua Jin of Jilin University. Human colon cancer cell line SW480 was obtained from the Department of Gastrointestinal Surgery, The First Bethune Hospital of Jilin University. Human colon cancer cell line HT29 (ATCC ${ }^{\circledR}$ HTB- $38^{\mathrm{TM}}$ ) was purchased from the American Type Culture Collection (ATCC; Manassas, VA, USA). Cells were cultured in McCoy's 5A medium modified (for HCT-116 and HT29) or Leibovitz's L-15 medium (for SW480) (both from Gibco, Grand Island, NY, USA) with $10 \%$ fetal bovine serum, $100 \mathrm{U} / \mathrm{ml}$ penicillin and $100 \mathrm{mg} / \mathrm{ml}$ streptomycin at $37^{\circ} \mathrm{C}$ in a humidified atmosphere of $5 \% \mathrm{CO}_{2}$. For transient transfection, the HCT-116 P53 ${ }^{-/}$cells were cultured and transfected with mutant p53 cDNAs in pcDNA3.1 plasmid using polyethylenimine (PEI). After $24 \mathrm{~h}$ of transfection, 5-fluorouracil (5-FU) and GLPs were added into the medium and incubated for another $24 \mathrm{~h}$. The cells were then analyzed by MTT assay or harvested and lysed for western blotting.

Cell viability and growth assay. For the viability assay, cells $\left(5 \times 10^{3}\right.$ cells/well) were seeded into $96-$ well plates and cultured overnight. Then, the cells were treated with 5-FU and GLPs. After $24 \mathrm{~h}$, cell proliferation and viability were determined by the MTT assay. Upon termination of treatment, MTT was applied to each well $(10 \mu \mathrm{l})$ at a final concentration of $0.5 \mathrm{mg} /$ $\mathrm{ml}$. After incubation for $4 \mathrm{~h}$ at $37^{\circ} \mathrm{C}$, the supernatant was removed and $100 \mu$ limethyl sulfoxide (DMSO) was applied, and the MTT-formazan products were extracted. The absorbance was read at $570 \mathrm{~nm}$ using a 96-well microplate reader (BioTek, Winooski, VT, USA).

For the growth assay, cells $\left(1 \times 10^{5}\right.$ cells/well $)$ were seeded in 6-well plates and cultured overnight. Then, the cells were treated with 5-FU and GLPs for up to $96 \mathrm{~h}$. Cell growth curves were plotted by trypan blue staining and cell counting (living cell number/well).

Isolation of mitochondrial fraction. Cells $\left(1 \times 10^{8}\right)$ were suspended in $2 \mathrm{ml}$ mitochondria isolation buffer $[0.225 \mathrm{M}$ mannitol, $0.075 \mathrm{M}$ sucrose, $1 \mathrm{mM}$ EGTA (pH adjusted to 7.4 with $0.5 \mathrm{M}$ Tris)] in a 10-ml Wheaton homogenizer tube and carefully homogenized for 30 strokes on ice. The cell debris was removed by centrifugation at 2,500 $\mathrm{rpm}(\sim 600 \mathrm{x} \mathrm{g})$ twice for $5 \mathrm{~min}$. The supernatant was filtered through a nylon screen cloth (Small Parts, Inc., Miami Lakes, FL, USA), and then centrifuged at $10,000 \mathrm{rpm}(\sim 9,000 \mathrm{xg})$ for $10 \mathrm{~min}$. The supernatant was maintained as the cytosolic fraction and the pellet was washed by adding $0.5 \mathrm{ml}$ of mitochondria isolation buffer and centrifuged at $10,000 \mathrm{rpm}$ for $5 \mathrm{~min}$. This washing step was repeated twice. The mitochondrial pellet was resuspended in 50-100 $\mu \mathrm{l}$ of mitochondria isolation buffer containing protease inhibitor cocktail (Research Products International Corp. Mount Prospect, IL, USA). The purity of the mitochondrial and cytosolic fractions was further examined by western blot analysis.

Western blotting. Whole cell lysate or the mitochondrial or cytosolic fractions from cultured cells was mixed with $4 \mathrm{X}$ SDS loading buffer $(0.25 \mathrm{M}$ Tris- $\mathrm{HCl} \mathrm{pH} 6.8,8 \%$ SDS, 30\% glycerol, $0.02 \%$ bromophenol blue containing 10\% BME), and boiled for $5 \mathrm{~min}$ at $95^{\circ} \mathrm{C}$. Denatured proteins were then separated by 12 or $18 \%$ SDS-PAGE, and specific proteins were detected using the indicated antibodies.

Apoptosis assays. Cells were collected and stained with the Annexin V-FLUOS staining kit (Roche) following the instructions for users. Sample cells were then analyzed using a FACS flow cytometer (Becton-Dickinson, Franklin Lakes, NJ, USA). We recorded Annexin V-positive and propidium iodide (PI)-negative cells as early stage apoptotic cells.

Cell cycle analysis. Cells $\left(1.0 \times 10^{6}\right)$ were harvested and rinsed with phosphate-buffered saline (PBS). The cell pellets were fixed in $70 \%$ ethanol at $4^{\circ} \mathrm{C}$ for $30 \mathrm{~min}$. After washing twice with PBS, the cells were stained with $1.0 \mathrm{ml}$ of PI solution (Dingguo Changsheng Biotechnology Co.,Ltd.,Beijing,China) containing $50 \mathrm{mg} / \mathrm{l}$ of PI and $10 \mathrm{mg} / \mathrm{l}$ of RNase, followed by incubation on ice in a dark condition for $30 \mathrm{~min}$. The samples were then analyzed by FACS (Becton-Dickinson).

In vitro cell-free apoptosis assays. Preparation of cytosol extract: $1 \times 10^{8}$ HCT-116 P53 ${ }^{-/}$cells were disrupted in $0.5 \mathrm{ml}$ of cytoplasmic extraction buffer (CEB) buffer (50 mM PIPES, pH 7.4, 50 mM KCI, 5 mM EGTA, 2 mM MgCl $2,1 \mathrm{mM}$ DTT, protease inhibitor cocktail) by freezing-thawing cycles with liquid nitrogen. The cell debris, organelles and nuclei were removed by centrifugation at $50,000 \mathrm{rpm}(\sim 300,000 \mathrm{x} \mathrm{g})$ for $1 \mathrm{~h}$. The supernatant was collected as the cytosol extract.

Preparation of nuclei extract: $2 \times 10^{7}$ HCT-116 $\mathrm{P}^{-/-}$cells were harvested and resuspended in $0.5 \mathrm{ml}$ of NEB buffer (10 mM HEPES, pH 7.9, $10 \mathrm{mM} \mathrm{KCl}, 1.5 \mathrm{mM} \mathrm{MgCl}{ }_{2}, 0.34 \mathrm{M}$ sucrose, $10 \%$ glycerol, $1 \mathrm{mM}$ DTT, $0.1 \%$ Triton X-100, protease inhibitor cocktail) and incubated on ice for $15 \mathrm{~min}$. Lysate was centrifuged at 3,500 $\mathrm{rpm}(\sim 1,200 \mathrm{xg})$ for $5 \mathrm{~min}$ and the pellet (nuclei) was washed and resuspended in DB buffer $(10 \mathrm{mM}$ HEPES, pH 7.0, $5 \mathrm{mM}$ EGTA, $50 \mathrm{mM} \mathrm{NaCl}, 2 \mathrm{mM} \mathrm{MgCl}$, $1 \mathrm{mM}$ DTT, protease inhibitor cocktail).

Basic reaction mix $(50 \mu \mathrm{l})$ was prepared with DB buffer containing the cytosol extract $(7.5 \mu \mathrm{g} / \mathrm{ml})$, mitochondrial extract $(40 \mu \mathrm{g} / \mathrm{ml}$, isolated as described above), dATP $(1 \mathrm{mM})$, phosphocreatine $(5 \mathrm{mM})$, creatine kinase $(25 \mu \mathrm{g} / \mathrm{ml})$ (all from Sigma), and nuclear extract $\left(1 \times 10^{6}\right.$ nuclei $\left./ \mathrm{ml}\right)$. Cytochrome $c$ $(10 \mu \mathrm{M})$ (Sigma; served as positive control for the assay), prokaryotically expressed p53 $(5 \mu \mathrm{g} / \mathrm{ml})$ and GLPs 

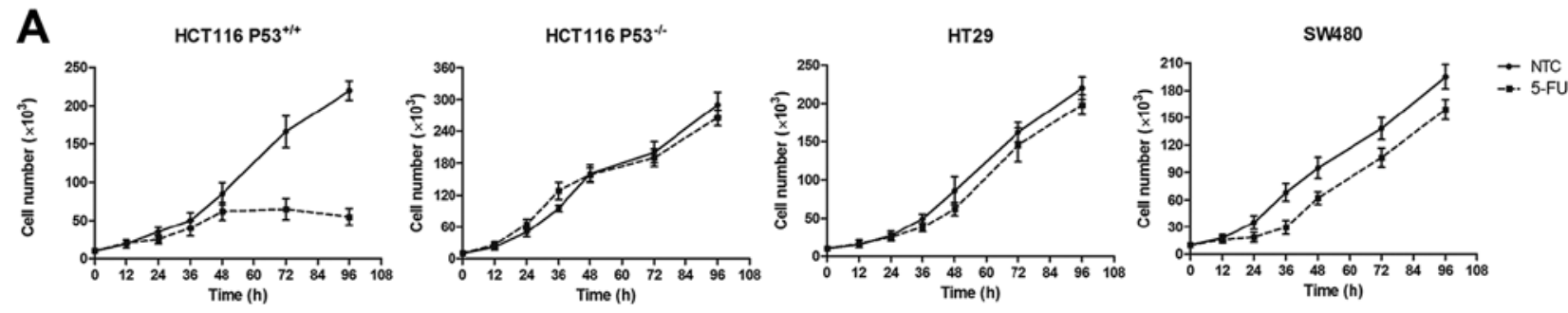

B

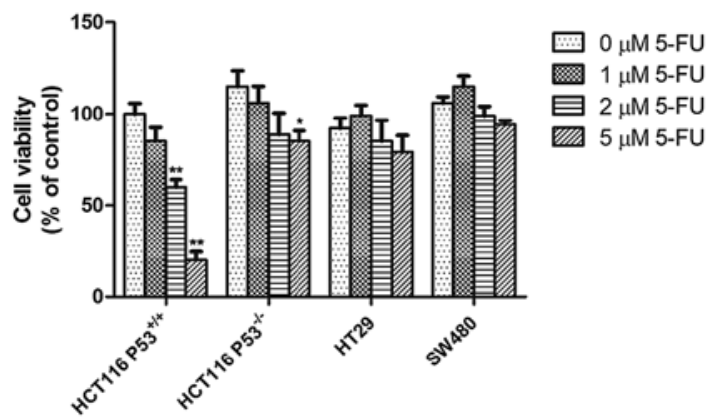

D

C

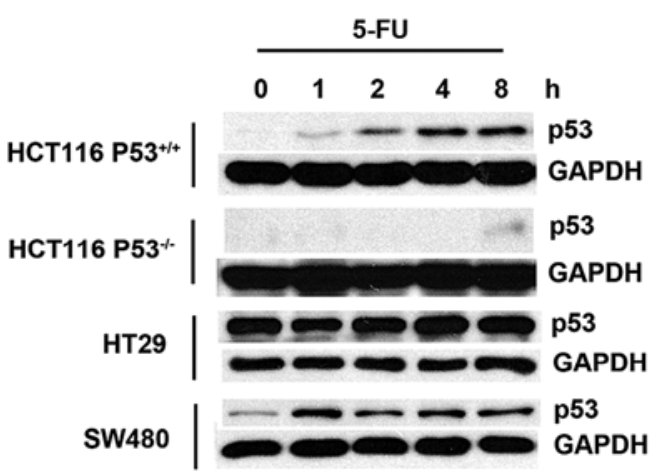

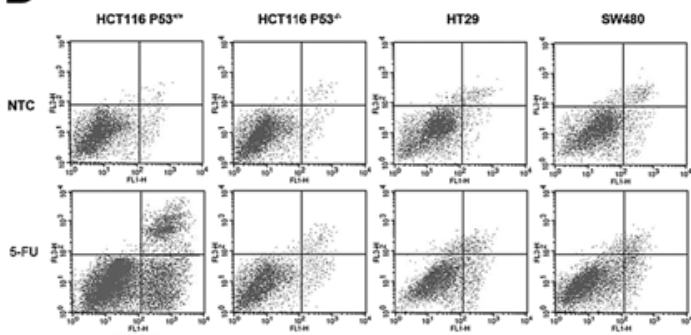

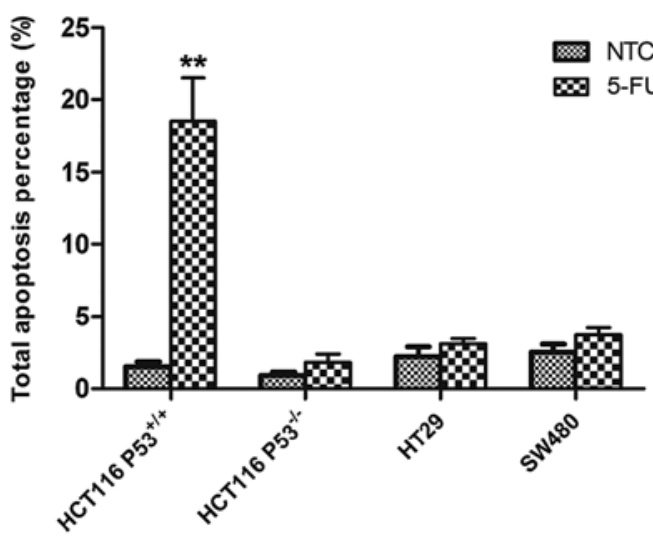

Figure 1. Wild-type p53 is essential for 5-FU-induced inhibition of colorectal cancer cells. (A) Growth curve of colorectal cancer cells treated with $5 \mu \mathrm{M}$ of 5-FU. (B) Cell viability of colorectal cancer cells treated with $0-5 \mu \mathrm{M}$ of 5-FU for $24 \mathrm{~h}$. (C) Whole cellular p53 protein level of colorectal cancer cells treated with $5 \mu \mathrm{M}$ of 5-FU. GAPDH served as a loading control. (D) Apoptosis of colorectal cancer cells treated with $5 \mu \mathrm{M}$ of 5 -FU for $24 \mathrm{~h}$. Data are reported as the mean \pm SEM $(n=3)$. NTC, no treatment control; ${ }^{*} \mathrm{p}<0.05,{ }^{* *} \mathrm{p}<0.01$ compared to the negative control.

$(100 \mu \mathrm{g} / \mathrm{ml})$ were added to the basic reaction mix with a designed combination. The final mix was incubated at $37^{\circ} \mathrm{C}$ for $4 \mathrm{~h}$. After reaction, the nuclei were collected and fixed with $4 \%$ paraformaldehyde solution (in PBS), and were then stained with 4',6-diamidino-2-phenylindole (DAPI) (H-1200; Vector Laboratories, Inc.). Fluorescence images of the nuclei were observed with an Olympus Bx40F microscope (Olympus Corporation, Tokyo, Japan). At least 500 nuclei were randomly counted and determined as being apoptotic or having a normal morphological phenotype.

Statistical analysis. Statistical analysis was achieved using GraphPad Prism 5 (GraphPad Software, Inc., La Jolla, CA, USA). Data are reported as the mean $\pm \operatorname{SEM}(n=3)$. Statistically significant differences were determined by one-way or two-way ANOVA tests. Values of $\mathrm{p}<0.05$ were considered to indicate a statistically significant result.

\section{Results}

Wild-type p53 is essential for 5-FU-induced inhibition of colorectal cancer cells. Initially, a series of studies of cell growth were performed to detect the response of the colorectal cancer cells bearing a different p53 status to 5-FU, a chemotherapy drug widely used in clinical practice for patients with colorectal cancer. An obvious growth inhibition was observed in the HCT-116 $\mathrm{P}^{2} 3^{+/+}$cells, a cell line expressing wild-type p53 (17), after treatment with $5 \mu \mathrm{M} 5$-FU. In contrast, the HCT-116 P53 ${ }^{--}$cells, a homogenous P53 gene-knockout cell line, exhibited resistance to 5-FU under the same treatment condition (Fig. 1A). Similar drug tolerance was also observed in the HT29 and SW480 cells (Fig. 1A); these two cell lines both express mutant p53 while HT29 carries a single mutation (R273H) and SW480 carries a double mutation (R273H and P309S) (18). To further confirm the role of p53 in 5-FU-mediated cell growth inhibition, we carried out an MTT assay to measure the viability of the cells treated with $0-5 \mu \mathrm{M}$ of $5-\mathrm{FU}$. As expected, only the cells with

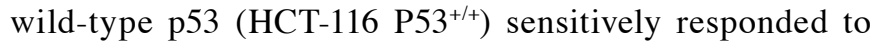
treatment with different concentrations of 5-FU in the MTT assay (Fig. 1B). Indeed, 5-FU treatment stabilized wild-type p53 in the HCT-116 cells (Fig. 1C, row 1) and thus probably triggered associated downstream cellular events such as apoptosis (Fig. 1D, column 1 and 2). Moreover, even though 
A

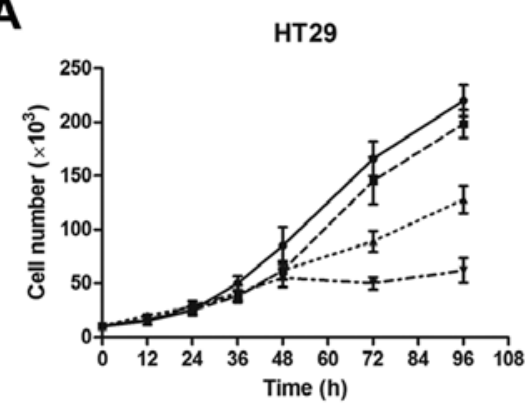

SW480

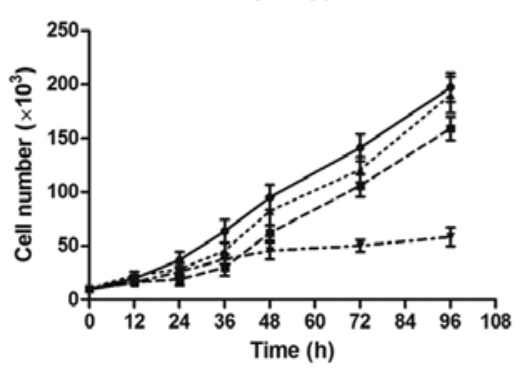

B

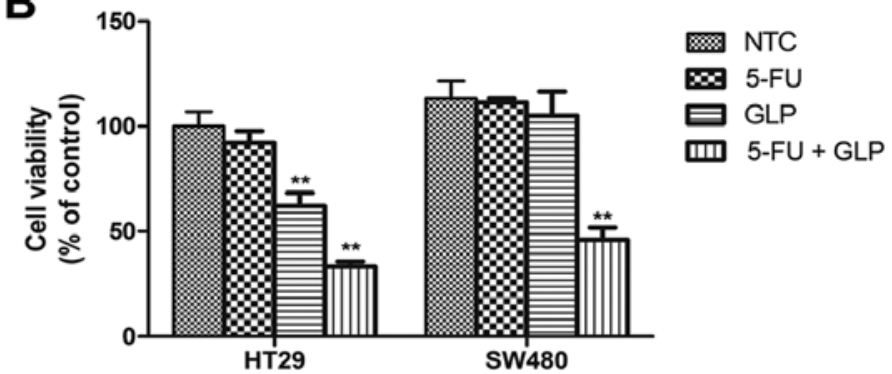

C

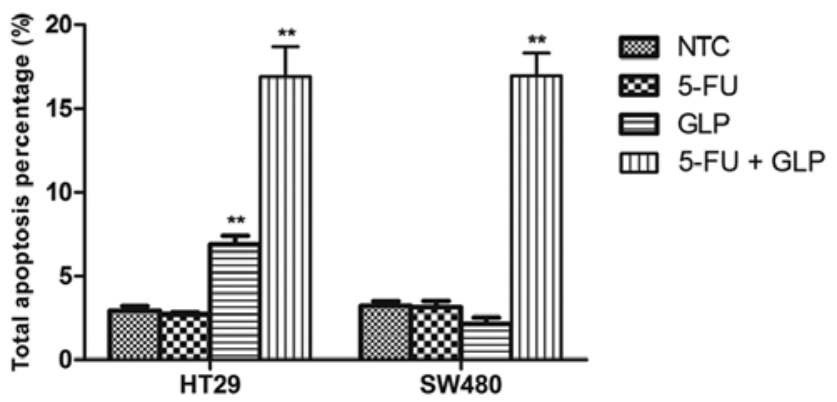

Figure 2. GLPs administered in combination with 5-FU synergistically suppress mutant p53-bearing colorectal cancer cells. (A) Growth curve of HT29 and SW480 cells treated with $5 \mu \mathrm{M} 5$-FU and/or $200 \mu \mathrm{g} / \mathrm{ml}$ of GLPs. (B) Cell viability of HT29 and SW480 cells treated with $5 \mu \mathrm{M} 5$-FU and/or $200 \mu \mathrm{g} / \mathrm{ml}$ of GLPs for $24 \mathrm{~h}$. (C) Apoptosis of HT29 and SW480 cells treated with $5 \mu \mathrm{M} 5$-FU and/or $200 \mu \mathrm{g} / \mathrm{ml}$ of GLPs for $24 \mathrm{~h}$. Data are reported as the mean \pm SEM $(\mathrm{n}=3)$. NTC, no treatment control; ${ }^{* *} \mathrm{p}<0.01$ compared to the negative control. GLP, Ganoderma lucidum polysaccharides.

the mutant p53 presented a different response pattern to 5-FU treatment (Fig. 1C, rows 5 and 7), there was no apoptosis signal detected in these two cell lines (Fig. 1D, column 5-8). It was also not surprising to find negative results for both the p53 protein level and the apoptosis signal in the 5-FU-treated HCT-116 P53 ${ }^{-1-}$ cells (Fig. 1C, row 3 and D, column 3 and 4). All these results indicate an important role of functional p53 and its tumor-suppressing effects in 5-FU treatment.

GLPs administered in combination with 5-FU synergistically suppress mutant p53-bearing colorectal cancer cells. In order to determine the relationship between the anticancer effects of GLPs and p53 status, we introduced GLPs to the treatment of mutant p53-bearing colorectal cancer cells with or without 5-FU co-treatment, since GLPs are widely used as an anticancer drug alone or combined with chemotherapeutics in many Asian countries. As shown in Fig. 2A and B, combined treatment with 5-FU and GLPs significantly suppressed the growth and viability of both mutant p53-bearing cancer cell lines compared to 5-FU treatment alone. These results suggest that GLPs may have a type of reactivating effect to mutant p53 that facilitates the p53-dependent tumor-suppressing activity of 5-FU. In line with that of the cell growth assay, the results of the apoptosis assay also showed a synergistic increase while introducing GLPs to 5-FU treatment (Fig. 2C). However, the effect of GLP treatment alone exhibited different results in the two cell lines tested. GLP treatment alone inhibited the growth and viability and triggered apoptosis of HT29 cells, while in contrast showed trivial effect on the SW480 cells (Fig. 2).

GLPs reactivate several types of exogenous mutant p53 in the HCT116 cells. It has been well documented that various types of p53 mutations that perturb p53 function exist in more than half of our known cancer cases (19). Thus, to evaluate the potential reactivating ability of GLPs on mutant p53, we constructed plasmids expressing exogenous p53 with different types of hot mutations and transfected HCT-116 $\mathrm{P}^{-/-}$cells with them, followed by treatment with 5-FU and GLPs in various combinations. All types of exogenous mutant p53 have a high level of basal expression so that 5-FU treatment did not induce further accumulation of whole cellular p53 in this situation (Fig. 3A). As revealed by the MTT assay, cell viability of the cells transfected with mutation R273H and R248W were significantly inhibited by GLPs either alone or combined with 5-FU (Fig. 3B). To confirm the reactivation of p53-mediated tumor-suppressing pathways, we performed western blot assay to measure the expression level of downstream genes that are regulated by p53. As shown in Fig. 3C, the expression of Bax and p21 were upregulated in the P53 ${ }^{\mathrm{R} 273 \mathrm{H}}$ and P53 ${ }^{\mathrm{R} 248 \mathrm{~W}}$ transfected cells after treatment with 5-FU and GLPs, suggesting a restoration of transactivation function to mutant p53 by GLPs. As two major downstream outputs of tumor-suppressor pathways, significant G1 arrest and apoptosis were also detected in the cells transfected with mutation P53 ${ }^{\mathrm{R} 273 \mathrm{H}}$ and P53 ${ }^{\mathrm{R} 248 \mathrm{~W}}$ (Fig. 3D and E), indicating full reactivation of $\mathrm{p} 53$ function.

GLPs facilitate the interaction between mutant p53 and mitochondria. In addition to the transactivation of downstream genes encoding proapoptotic proteins, p53 is also able to physically interact with mitochondria and induce apoptosis through a so called transcriptional-independent pathway (20-22). To investigate whether or not the transcriptionalindependent apoptotic pathway is involved in GLP-mediated 
A

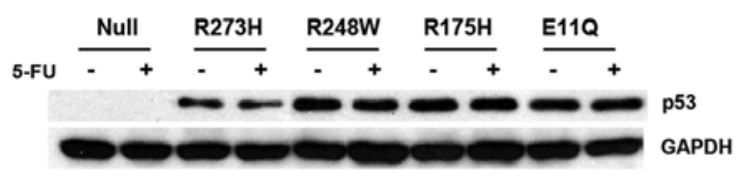

B

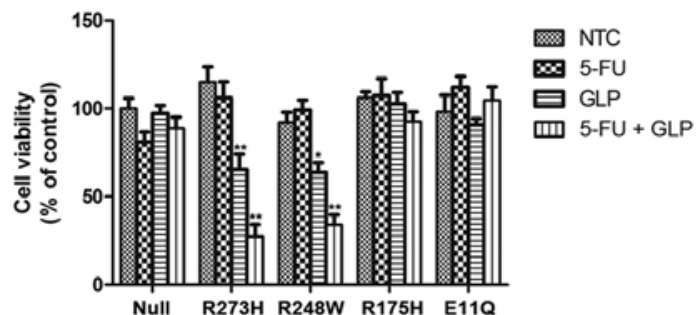

C

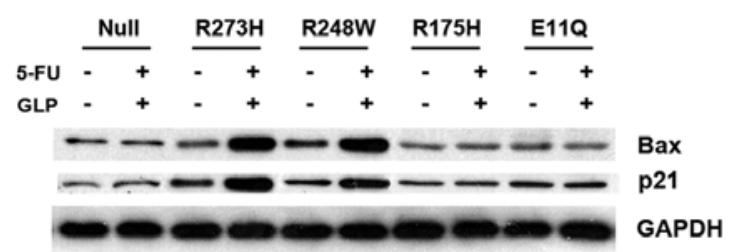

D

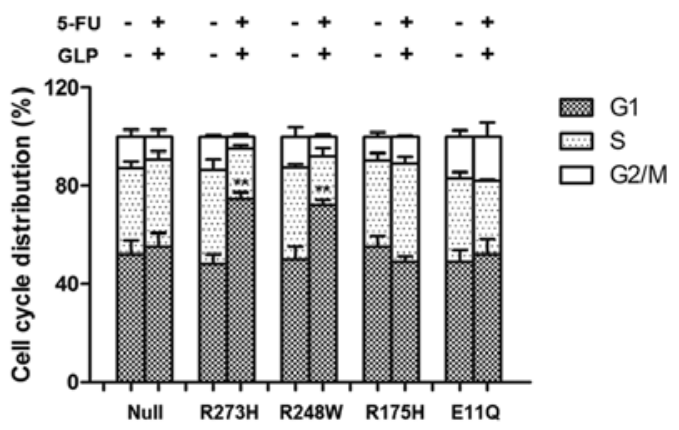

$\mathbf{E}$

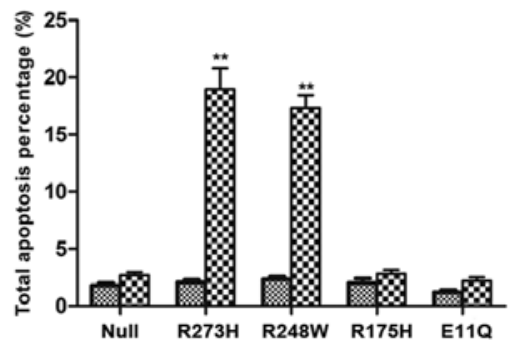

Figure 3. GLPs reactivate several types of exogenous mutant p53 in HCT116 cells. (A) Whole cellular protein level of exogenous mutant p53 in HCT116 $\mathrm{P}^{-/}{ }^{-/}$cells treated with $5 \mu \mathrm{M} 5$-FU for $8 \mathrm{~h}$. (B) Cell viability of mutant p53-transfected HCT116 P53 ${ }^{-/}$cells treated with $5 \mu \mathrm{M} 5-\mathrm{FU}$ and/or $200 \mu \mathrm{g} / \mathrm{ml}$ of GLPs for $24 \mathrm{~h}$. (C) Protein expression level of p53 target genes, Bax and p21, in mutant p53-transfected HCT116 P53 ${ }^{-\digamma}$ cells treated with $5 \mu \mathrm{M} \mathrm{5-FU} \mathrm{and} 200 \mu \mathrm{g} / \mathrm{ml}$ of GLPs for $24 \mathrm{~h}$. (D) Histogram of cell cycle distribution of mutant p53-trasfected HCT116 P53 ${ }^{-/}$cells treated with $5 \mu \mathrm{M}$ of 5 -FU and $200 \mu \mathrm{g} / \mathrm{ml}$ of GLPs for $24 \mathrm{~h}$. (E) Apoptosis of mutant p53-transfected HCT116 P53 ${ }^{-/}$cells treated with $5 \mu \mathrm{M} 5-\mathrm{FU}$ and $200 \mu \mathrm{g} / \mathrm{ml}$ of GLPs for $24 \mathrm{~h}$. Data are reported as the mean \pm SEM $(n=3)$. NTC, no treatment control; Null, no transfection control; ${ }^{*} \mathrm{p}<0.05,{ }^{*} \mathrm{p}<0.01$ compared to the negative control. GAPDH served as a loading control. GLP, Ganoderma lucidum polysaccharides.

mutant p53 reactivation, we designed a series of assays that bypass the nuclear 553 function. Cellular components from the cytosol and mitochondria were respectively separated with differential centrifugation (Fig. 4A) and the levels of the proteins of interest were detected with specific antibodies. As shown in Fig. 4C, in the SW480 cells, 5-FU treatment induced whole cellular accumulation of mutant $\mathrm{p} 53$, and in the meantime a fraction of mutant p53 translocated to thevmitochondria. This distribution pattern of mutant $\mathrm{p} 53$ was further strengthened by adding GLPs to the treatment, indicating that GLPs facilitated 5-FU-induced p53 mitochondrial translocation. It is believed that functional p53 translocating to mitochondria can interact with Bax, a Bcl-2 family protein, and thus induce mitochondrial membrane permeabilization (MMP) and cytochrome $c$ release $(23,24)$. In SW480 cells, mutant p53 accumulation in the mitochondria by 5 -FU treatment was not sufficient to induce cytochrome $c$ release (Fig. 4B, lane 2). However, co-treatment with GLPs resulted in obvious cytochrome $c$ release which was clearly detected in both mitochondrial and cytosolic fraction (Fig. 4B, lane 4), suggesting the restoration of the p53 ability to regulate Bax and MMP by GLPs. To further exclude the influence of the transactivation effect of p53, we introduced an in vitro cell-free system to determine the regulatory role of GLPs in the interaction between p53 and mitochondria. Isolated nuclei, cytosol and mitochondria from HCT-116 P53 ${ }^{--}$cells were mixed together and incubated with prokaryotically expressed p53 and GLPs. After interaction between 533 and mitochondria, cytochrome $c$ released from mitochondria activated the downstream caspase cascade and eventually induced chromatin condensing and bubbling of isolated nuclei (Fig. 4D). Based on this in vitro assay system, our results showed that wild-type p53 induced MMP and cytochrome $c$ release, while in contrast mutant $\mathrm{p} 53^{\mathrm{R} 273 \mathrm{H}}$ lacked this activity but was reactivated by GLPs (Fig. 4E).

\section{Discussion}

Polysaccharides, along with triterpenes, are regarded as major biologically active compounds in Ganoderma lucidum (25). The most frequent classes of polysaccharides isolated from Ganoderma lucidum are glucans, glycoproteins, glycopeptides and water-soluble heteropolysaccharides (26). Although GLPs have been proven to possess strong anticancer effects, the anticancer effects of GLPs are generally believed to depend on modulation of immune cell response, which further targets cancer cells (27). Specifically, GLPs affect immune cells and immune-related cells such as T and B lymphocytes, macrophages, dendritic and natural killer cells (9). However, whether GLPs have an anticancer effect that is independent of its immunostimulatory effects remain unclarified. Several pharmacological studies have revealed that GLPs are able to directly suppress the proliferation of various types of cancer cell lines $(10-12,28)$, but the mechanisms underlying the cytotoxic and cytostatic activities are yet to be determined.

p53 is a potent tumor suppressor which can prevent the propagation of cells carrying oncogenic lesions via a multitude of pathways such as growth arrest, senescence or apoptosis, modulation of tumor stroma, angiogenesis and metabolism, as well as the blockage of invasion and metastasis (29). This explains why loss of p53 function is opted for during tumor 
A

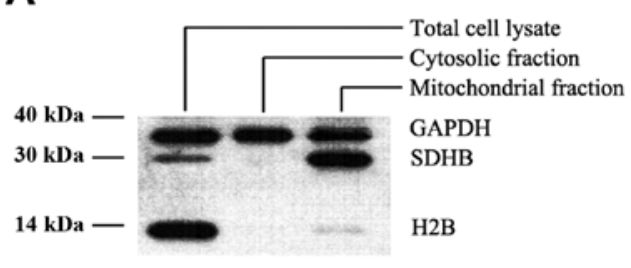

B

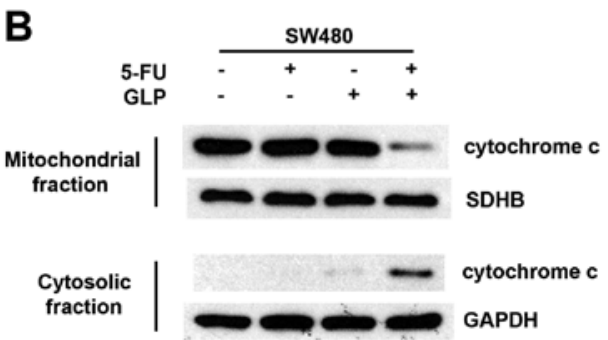

C

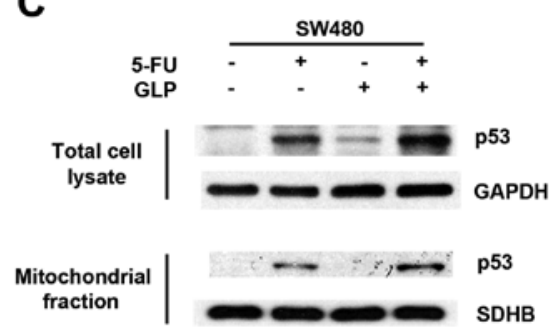

D

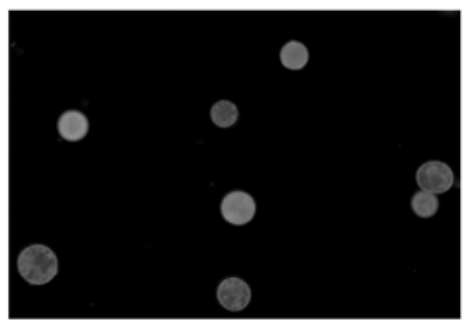

Basic reaction mix

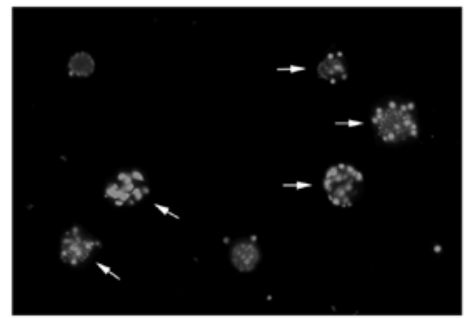

Basic reaction mix + cytochrome c

E

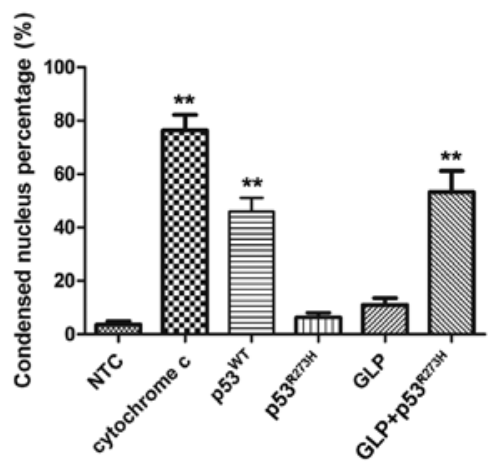

Figure 4. GLPs facilitate the interaction between mutant p53 and mitochondria. (A) Quality of isolated mitochondria from SW480 cells, revealed by protein level of GAPDH, SDHB and H2B in every fraction. (B) Cytochrome $c$ release from mitochondria to the cytosol in SW480 cells treated with $5 \mu \mathrm{M} 5$-FU and/or $200 \mu \mathrm{g} / \mathrm{ml}$ of GLPs for $24 \mathrm{~h}$. (C) Whole cellular and mitochondrial p53 protein level of SW480 cells treated with $5 \mu \mathrm{M} 5$-FU and $/ \mathrm{or} 200 \mu \mathrm{g} / \mathrm{ml}$ of GLPs for 8 h. (D) Typical images of nuclei with normal (upper panel) or apoptotic (lower panel) morphological phenotype from cell-free apoptosis assay. Apoptotic nuclei are indicated with white arrows. (E) Percentage of condensed nuclei in the cell-free apoptosis assay system added with $10 \mu \mathrm{M}$ of cytochrome, $5 \mu \mathrm{g} / \mathrm{ml}$ of prokaryotically expressed $\mathrm{p} 53$ and $100 \mu \mathrm{g} / \mathrm{ml}$ of GLPs with the indicated combination. Data are reported as the mean \pm SEM $(\mathrm{n}=3) ;{ }^{* *} \mathrm{p}<0.01$ compared to the negative control. GAPDH and SDHB served as a loading control. GLP, Ganoderma lucidum polysaccharides.

development, resulting in p53 inactivation in the majority of human tumors $(19,30)$. Therefore, restoration of mutant p53 function in tumor cells could be an attractive and specific strategy for treating cancer. Indeed, it has already been reported that various natural or artificially synthesized compounds are able to reactivate mutant p53 in tumor cells (31-34).

In the present study, we demonstrated a direct reactivation effect of GLPs on mutant p53 in colorectal cancer cells. This reactivation effect influenced both the transcriptional and non-transcriptional activities of p53. It is notable that in the absence of 5-FU, GLPs alone were not sufficient to induce growth inhibition and apoptosis in the SW480 cells (Figs. 2 and 4C), while in contrast, it was effective in the HT29 cells (Fig. 2), exogenous mutant p53-transfected HCT-116 P53 ${ }^{-/}$cells (Fig. 3B), as well as in vitro cell-free system (Fig. 4E). In addition, an obvious difference between SW480 cells and other experimental models is that there is no or little p53 protein accumulated without 5-FU treatment (Figs. 1C and 3A). Thus, it is reasonable to speculate that GLPs can reactivate mutant p53 that must already exist abundantly at the right location in the cell, but may lose target whether the cells lack appropriate p53 accumulation or localization, which may be triggered by other stimuli such as 5-FU through post-translational modification of p53 or other pathways. Another point worth noting is the target site of GLPs on mutant p53. In the present study, using 4 different types of hot mutations of p53, only R273H and R248W were sensitive to GLP treatment, which are both mutations in the DNA binding domain (Fig. 3). This result indicates strong target site specificity of GLP-mediated mutant p53 reactivation and suggests further structural studies to verify the interaction model between GLPs and major hot mutations of p53.

In conclusion, the present study offers a novel insight into the mechanism of GLP-induced cytotoxicity and apoptosis in human colorectal cancer cells, suggesting promising usage of GLPs along with other chemotherapeutics to reactivate mutant p53 in the treatment of cancer. Our results also provide potential perspectives for further research on the pharmacology of GLPs as a possible candidate for cancer prevention or treatment of cancer with mutant p53. 


\section{Acknowledgements}

The present study was supported by Jilin Province Science and Technology Development Program (20140520005JH), the National Natural Science Foundation of China (31100999), and the China Postdoctoral Science Foundation Grant (2014M561288).

\section{References}

1. Wang XC, Xi RJ, Li Y, Wang DM and Yao YJ: The species identity of the widely cultivated Ganoderma, 'G. lucidum' (Ling-zhi), in China. PLoS One 7: e40857, 2012.

2. Li J, Zhang J, Chen H, Chen X, Lan J and Liu C: Complete mitochondrial genome of the medicinal mushroom Ganoderma lucidum. PLoS One 8: e72038, 2013.

3. Shiao MS: Natural products of the medicinal fungus Ganoderma lucidum: Occurrence, biological activities, and pharmacological functions. Chem Rec 3: 172-180, 2003.

4. Gordan JD, Chay WY, Kelley RK, Ko AH, Choo SP and Venook AP: 'And what other medications are you taking?' J Clin Oncol 29: e288-e291, 2011.

5. Papadopoulos I, Guo F, Lees S and Ridge M: An exploration of the meanings and experiences of cancer of Chinese people living and working in London. Eur J Cancer Care 16: 424-432, 2007.

6. Sliva D: Ganoderma lucidum (Reishi) in cancer treatment. Integr Cancer Ther 2: 358-364, 2003.

7. Batra P, Sharma AK and Khajuria R: Probing Lingzhi or Reishi medicinal mushroom Ganoderma lucidum (higher Basidiomycetes): A bitter mushroom with amazing health benefits. Int J Med Mushrooms 15: 127-143, 2013.

8. Wachtel-Galor S, Yuen J, Buswell JA and Benzie IFF: Ganoderma lucidum (Lingzhi or Reishi): A Medicinal Mushroom. In: Herbal Medicine: Biomolecular and Clinical Aspects. Benzie IFF and Wachtel-Galor S (eds). Chapter 9. 2nd edition. CRC Press/Taylor \& Francis, Boca Raton, FL, 2011. http://dx.doi.org/10.1201/b10787.

9. Xu Z, Chen X,Zhong Z, Chen L and Wang Y: Ganoderma lucidum polysaccharides: Immunomodulation and potential anti-tumor activities. Am J Chin Med 39: 15-27, 2011.

10. Shang D, Li Y, Wang C, Wang X, Yu Z and Fu X: A novel polysaccharide from Se-enriched Ganoderma lucidum induces apoptosis of human breast cancer cells. Oncol Rep 25: 267-272, 2011.

11. Huang CY, Chen JY, Wu JE, Pu YS, Liu GY, Pan MH, Huang YT, Huang AM, Hwang CC, Chung SJ, et al: Ling-Zhi polysaccharides potentiate cytotoxic effects of anticancer drugs against drug-resistant urothelial carcinoma cells. J Agric Food Chem 58: 8798-8805, 2010.

12. Wang J, Zhang L, Yu Y and Cheung PC: Enhancement of antitumor activities in sulfated and carboxymethylated polysaccharides of Ganoderma lucidum. J Agric Food Chem 57: 10565-10572, 2009.

13. Boh B: Ganoderma lucidum: A potential for biotechnological production of anti-cancer and immunomodulatory drugs. Recent Patents Anticancer Drug Discov 8: 255-287, 2013.

14. JinX, Ruiz Beguerie J, Sze DM and Chan GC: Ganodermalucidum (Reishi mushroom) for cancer treatment. Cochrane Database Syst Rev 6: CD007731, 2012.

15. Zhang J, Chen JM, Wang XX, Xia YM, Cui SW, Li J and Ding ZY: Inhibitor or promoter? The performance of polysaccharides from Ganoderma lucidum on human tumor cells with different p53 statuses. Food Funct 7: 1872-1875, 2016.
16. Liang Z, Guo YT, Yi YJ, Wang RC, Hu QL and Xiong XY: Ganoderma lucidum polysaccharides target a Fas/caspase dependent pathway to induce apoptosis in human colon cancer cells. Asian Pac J Cancer Prev 15: 3981-3986, 2014.

17. Liu Y and Bodmer WF: Analysis of P53 mutations and their expression in 56 colorectal cancer cell lines. Proc Natl Acad Sci USA 103: 976-981, 2006.

18. Nigro JM, Baker SJ, Preisinger AC, Jessup JM, Hostetter R, Cleary K, Bigner SH, Davidson N, Baylin S, Devilee P, et al: Mutations in the p53 gene occur in diverse human tumour types. Nature 342: 705-708, 1989.

19. Hainaut $P$ and Hollstein M: p53 and human cancer: The first ten thousand mutations. Adv Cancer Res 77: 81-137, 2000.

20. Vousden KH and Lane DP: p53 in health and disease. Nat Rev Mol Cell Biol 8: 275-283, 2007.

21. Mihara M, Erster S, Zaika A, Petrenko O, Chittenden T, Pancoska P and Moll UM: p53 has a direct apoptogenic role at the mitochondria. Mol Cell 11: 577-590, 2003.

22. Moll UM, Wolff S, Speidel D and Deppert W: Transcriptionindependent pro-apoptotic functions of p53. Curr Opin Cell Biol 17: 631-636, 2005.

23. Chipuk JE, Kuwana T, Bouchier-Hayes L, Droin NM, Newmeyer DD, Schuler M and Green DR: Direct activation of Bax by 553 mediates mitochondrial membrane permeabilization and apoptosis. Science 303: 1010-1014, 2004.

24. Chipuk JE and Green DR: Cytoplasmic p53: Bax and forward. Cell Cycle 3: 429-431, 2004.

25. Boh B, Berovic M, Zhang J and Zhi-Bin L: Ganoderma lucidum and its pharmaceutically active compounds. Biotechnol Annu Rev 13: 265-301, 2007.

26. Chen Y, Xie MY, Wang YX, Nie SP and Li C: Analysis of the monosaccharide composition of purified polysaccharides in Ganoderma atrum by capillary gas chromatography. Phytochem Anal 20: 503-510, 2009

27. Lin ZB: Cellular and molecular mechanisms of immuno-modulation by Ganoderma lucidum. J Pharmacol Sci 99: 144-153, 2005.

28. Li N, Hu YL, He CX, Hu CJ, Zhou J, Tang GP and Gao JQ: Preparation, characterisation and anti-tumour activity of Ganoderma lucidum polysaccharide nanoparticles. J Pharm Pharmacol 62: 139-144, 2010.

29. Vousden KH and Prives C: Blinded by the light: The growing complexity of p53. Cell 137: 413-431, 2009.

30. Lawrence MS, Stojanov P, Polak P, Kryukov GV, Cibulskis K, Sivachenko A, Carter SL, Stewart C, Mermel CH, Roberts SA, et al: Mutational heterogeneity in cancer and the search for new cancer-associated genes. Nature 499: 214-218, 2013.

31. Bykov VJ, Issaeva N, Shilov A, Hultcrantz M, Pugacheva E, Chumakov P, Bergman J, Wiman KG and Selivanova G: Restoration of the tumor suppressor function to mutant $\mathrm{p} 53$ by a low-molecular-weight compound. Nat Med 8: 282-288, 2002.

32. Wang F, Liu J, Robbins D, Morris K, Sit A, Liu YY and Zhao Y: Mutant p53 exhibits trivial effects on mitochondrial functions which can be reactivated by ellipticine in lymphoma cells. Apoptosis 16: 301-310, 2011.

33. Liu X, Wilcken R, Joerger AC, Chuckowree IS, Amin J, Spencer J and Fersht AR: Small molecule induced reactivation of mutant p53 in cancer cells. Nucleic Acids Res 41: 6034-6044, 2013.

34. Selivanova G and Wiman KG: Reactivation of mutant p53: Molecular mechanisms and therapeutic potential. Oncogene 26 : 2243-2254, 2007. 